\title{
O ESTÁGIO OBRIGATÓRIO NO CURSO DE GEOGRAFIA NA UEG CÂMPUS FORMOSA um componente instigando a formação crítica e reflexiva?
}

\author{
Francilane Eulália de Souza ${ }^{1}$
}

Resumo: Posto que o estágio é momento privilegiado de experimentação docente, o mesmo precisa estar alicerçado em teorias e práticas que possibilitam ao aluno pensar a si mesmo numa perspectiva investigativa da sua própria ação. O objetivo desse artigo é apresentar o caminhar do estágio supervisionado obrigatório, desenvolvido no curso de licenciatura em Geografia da UEG Câmpus Formosa, para uma perspectiva investigativa e crítica da formação docente. A principal metodologia foi a pesquisa bibliográfica e documental, assim como a pesquisa de campo. As teorias da representação social foram aqui tomadas como instrumento para analisar como alunos vêm representando o estágio supervisionado. Por fim, embora esse componente tenha apresentado uma transformação qualitativa, ainda podemos afirmar que suas práxis carecem de ações alicerçadas no diálogo entre os sujeitos que executam esse componente pedagógico para, assim, superar os desafios ainda presentes.

Palavras-chave: Estágio. Geografia. Representação social.

\section{THE MANDATORY INTERNSHIP IN THE GEOGRAPHY GRADUATION COURSE IN UEG CÂMPUS FORMOSA a exciting component to the critical and reflective formation?}

\begin{abstract}
Since the internship is a privileged moment of teacher experimentation, it must be based on theories and practices that allow the student to think of himself in a research perspective of his own action. The objective of this article is to present the path of the compulsory supervised internship, developed in the degree course in Geography of the UEG Campus Formosa, for a research and critical perspective of teacher education. The main methodology was the bibliographical and documentary research, as well as the field research. Theories of social representation were taken here as an instrument to analyze how students have represented the supervised internship. Finally, although this component has presented a qualitative transformation, we can still affirm that its praxis lack actions based on the dialogue between the subjects that execute this pedagogical component in order to overcome the challenges still present.
\end{abstract}

Keywords: Internship. Geography. Social Representation.

\section{INTRODUÇÃO}

O estágio é importante para a formação de professores na medida em que lhes possibilita um primeiro contato com sua futura profissão. Constitui, também, o momento

\footnotetext{
${ }^{1}$ Doutora em Geografia pela UNESP - Presidente Prudente e Mestre em Geografia pela Universidade Federal de Goiás (2003). Graduação em licenciatura em Geografia pela Universidade Federal de Uberlândia (1999). Bacharelado em Geografia pela Universidade Federal de Uberlândia (2001). Atualmente é professora da Universidade Estadual de Goiás Campus Formosa. Líder do GEPER - Grupo de Estudo e Pesquisa do Espaço Rural. E-mail: francilanee@ hotmail.com
} 


\section{REVISTA ELETRÔNICA \\ DA GRADUAÇÃO/PÓS-GRADUAÇÃO EM EDUCAÇÃO \\ UFG/REJ}

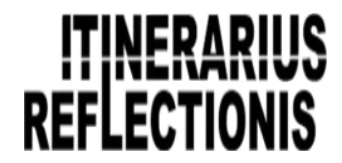

ISSN. 1807-9342

Volume 14, N. 2, 2018

teórico-prático do curso, em que o aluno, amparado pelos componentes pedagógicos que compõem o curso, reflete sobre sua formação, tencionando colocar em prática suas competências e habilidades. Nesse sentido, o estágio, numa perspectiva crítica e reflexiva, é de suma importância para a formação de professores; ignorar essa importância faz com que, dentre outros fatores, os futuros professores não consigam compreender a complexidade da aprendizagem.

Para Pimenta e Lima (2004), o estágio por vezes tem sido identificado erroneamente apenas como a parte prática dos cursos de formação de professores, ao mesmo tempo em que muitos cursos, na sua matriz curricular, enfatizam um aglomerado de disciplinas isoladas entre si, sem articular a teoria e a prática. É possível ir mais longe, e afirmar que teoria e prática se traduzem em espaços desiguais de poder na estrutura curricular, atribuindo-se menor importância à parte teórica, o que muitas vezes torna o estágio burocrático e enfadonho.

Por outro lado, as teorias e legislações ligadas ao estágio supervisionado em licenciatura têm estimulado, ao longo do tempo, um avanço qualitativo nos estágios. Temse buscado melhorar a qualidade da formação dos profissionais da educação, incorporando-se uma perspectiva reflexiva, que possibilita a superação entre a dicotomia teoria e a prática, objetivando a formação de professores capazes de desenvolver o estágio numa perspectiva crítica e reflexiva, ressignificando a prática docente a cada investigação proposta.

A Universidade Estadual de Goiás também se insere nesse contexto. Ao longo de seus quase 19 anos de formação, o estágio obrigatório em licenciatura passou por diversas transformações a partir da constituição de cadernos de orientações e Resolução destinadas aos mesmos; não obstante, esse componente pedagógico ainda enfrenta desafios quando se pensa na implementação de um estágio pautado na formação crítica e reflexiva.

Nesse contexto, o objetivo nesse artigo é apresentar o caminhar do estágio supervisionado obrigatório desenvolvido no curso de licenciatura em Geografia da Universidade Estadual de Goiás - Câmpus Formosa, que, nos últimos anos, vem sendo objeto de nossas pesquisas.

A metodologia adotada foi a pesquisa bibliográfica e documental, assim como a pesquisa de campo, com entrevista aos alunos ligados ao estágio supervisionado em Geografia. Também as teorias da representação social foram aqui tomadas como 


\section{REVISTA ELETRÔNICA \\ DA GRADUAÇÃO/PÓS-GRADUAÇÃO EM EDUCAÇÃO UFG/REJ}

\section{ITEERPUUS REFLECTIONIS}

ISSN. 1807-9342

Volume 14, N. 2, 2018

instrumento para se pensar como alunos e professores têm representado o estágio supervisionado.

As análises aqui apresentadas podem contribuir para que o curso de licenciatura em Geografia repense as formas de desenvolver o estágio, pois vem refletindo sobre o estágio na perspectiva crítico-reflexiva, apontando, dentre outros elementos, a representação social dos alunos sobre o estágio.

\section{O CAMINHO DA PESQUISA}

O estágio em licenciatura é um componente pedagógico complexo e dinâmico, afinal, está inserido na realidade não só dos cursos de formação de professores, mas também na realidade das escolas. As reflexões que aqui apresentamos se relacionam a diversas inquietações ligadas ao estágio do curso de licenciatura em Geografia da Universidade Estadual de Goiás, no Câmpus de Formosa. Embora nossa pesquisa seja, de fato, mais ampla e abarque outros campi e sujeitos, apresentamos, no momento, parte dela, priorizando a representação dos alunos ligados ao estágio em Geografia somente no Câmpus supracitado.

Assim, aglutinamos aqui resultados de pesquisa realizada em dois momentos, quais sejam, nos anos 2012 e 2013, e nos anos 2016 e 2017. Somamos, assim, quatro anos de pesquisa que possibilitaram o acompanhamento de mudanças que ocorreram nesse intervalo, bem como a avaliação do impacto dessas mudanças na representação social ligada ao estágio no curso de licenciatura em Geografia. É importante também destacar que essas pesquisas foram aprovadas na Pró-reitoria de Pesquisa da UEG por meio de projetos, seguindo todos os trâmites de uma pesquisa acadêmica.

Quanto à metodologia, a pesquisa bibliográfica sobre o estágio supervisionado voltado para a formação de professores foi, a princípio, muito importante. A pesquisa de campo também desempenhou papel fundamental, na medida em que fizemos uso de instrumentos tais como entrevistas com alunos que já estavam realizando o estágio obrigatório, a fim de analisar a representação social dos mesmos sobre o estágio.

No ano de 2012 e 2013, realizamos pesquisa direta e indireta. A partir de outubro e novembro de 2012, a pesquisa de campo consistiu na aplicação de roteiros de entrevista, que compreendia aspectos socioeconômicos, sobre o curso e sobre o estágio 


\section{REVISTA ELETRÔNICA \\ DA GRADUAÇÃO/PÓS-GRADUAÇÃO EM EDUCAÇÃO \\ UFG/REJ}

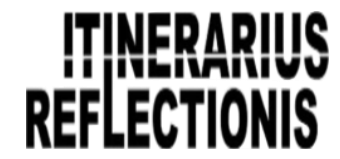

ISSN. 1807-9342

Volume 14, N. 2, 2018

supervisionado. Na turma do $4^{\circ}$ ano, foram entrevistados 8 alunos de um total de 24 , enquanto na turma do $3^{\circ}$ ano, 25 alunos de um total de 35 , de modo que nossa investigação contemplou aproximadamente $56 \%$ dos alunos que executaram o estágio naquele período.

Nos anos de 2016 e 2017, todos os 23 alunos frequentes da turma do $3^{\circ}$ ano do curso de licenciatura em Geografia foram entrevistados. Da turma do $4^{\circ}$ ano, que era composta por 14 alunos frequentes, 13 responderam o roteiro. A pesquisa, assim, considerou quase $100 \%$ desses discentes.

Analisamos, também, diversas documentações ligadas ao estágio, tal como o Caderno 2 de orientação do estágio e a Resolução CsA 854/2015, que possibilitaram o entendimento das principais mudanças relacionadas a esse componente nos últimos anos.

Notamos, ainda, que essa pesquisa é parte de um recorte temporal, de uma realidade em constante transformação, que requer, também, constante avaliação e reflexão, no sentido de qualificar cada vez mais a formação de professores, e, logo, a mesma se situa num tempo-espaço conflituoso. Ao passo que os pesquisadores estão envolvidos diretamente no estágio, objeto dessa investigação-reflexão da própria ação, também à pesquisa se confere a perspectiva da ação-reflexão-ação, que certamente proporcionará a possibilidade de avaliar e alterar as ações diretamente ligadas ao estágio, o que confere, à metodologia dessa pesquisa, caráter de constante avaliação e reflexão.

Iniciamos, assim, as reflexões desse artigo apresentando a UEG e sua política de estágio, visto que as mesmas são documentos importantes que impulsionam transformações e, logo, ações nesse componente - daí também sua importância.

\section{A UEG E SUAS POLÍticas DE ESTÁGIO SUPERVISIONADO EM LICENCIATURA}

\section{Breves considerações sobre a Universidade Estadual de Goiás}

A Universidade Estadual de Goiás foi fundada pela Lei nº 13.456 , de 16 de abril de 1999. Atualmente, a Universidade Estadual de Goiás é constituída por 42 Campi Universitários em 39 municípios do estado de Goiás, tendo como sede a Unidade de Anápolis. Em toda a UEG, são oferecidos mais de 130 cursos, dos quais 10 são de Licenciatura Plena em Geografia. 


\section{REVISTA ELETRÔNICA \\ DA GRADUAÇÃO/PÓS-GRADUAÇÃO EM EDUCAÇÃO \\ UFG/REJ}

\section{ITEERPUW \\ REFLECTIONIS}

ISSN. 1807-9342

Volume 14, N. 2, 2018

Desde sua criação, essa Universidade vem buscando mecanismos para se consolidar enquanto tal, tendo ampliado tanto o quadro de servidores efetivos como os programas de pós-graduação - contando, atualmente, com cursos de doutorado em Ciências ambientais e Química -, implementado bolsa permanente para quase 600 alunos, bem como bolsas de incentivos aos pesquisadores, dentre outras ações. No entanto, apesar de seus esforços, a UEG ainda encara diversas dificuldades para se manter no cenário educacional brasileiro, o que se deve, em parte, ao seu papel no cenário políticogovernamental, que ora a coloca à disposição das políticas do estado, ora das políticas do governo. Dentre essas, se destacam negativamente a expansão dos campi universitários, quando, ao contrário, um enxugamento dos mesmos possibilitaria priorizar a qualidade da infraestrutura, do material humano e, logo, do ensino.

Podemos citar alguns problemas mais pontuais como a infraestrutura precária da Universidade desde sua constituição. A UEG foi estabelecida em prédios pensados apenas para abrigar salas de aula, de modo que não raro os campi não possuem espaços para atividades práticas como laboratórios, orientação de alunos, exercícios de pesquisa e extensão e, chegando ao ponto de, em alguns casos, sequer haver sala de professores e coordenadores. Os espaços das bibliotecas são insuficientes até para abrigar o acervo bibliográfico que, por sua vez, também é insuficiente para se pensar um ensino de qualidade. A maioria das bibliotecas não consegue atender sequer as bibliografias básicas dos cursos.

Aos problemas supracitados soma-se, ainda, a deterioração da infraestrutura já existente. Não obstante, em função do quantitativo de campi, alguns vem se destacando por abrigar uma infraestrutura com menos problemas.

Quando se fala em Gestão, até 2012 a UEG foi dirigida por Reitores que faziam parte do quadro temporário comissionado, fato muito comum nos campi que também eram dirigidos por diretores do quadro de temporário, muitos com apenas especialização. Até o momento, no entanto, essa prática parece ter sido freada meio de resolução própria da UEG.

Outro fato preocupante diz respeito aos servidores que são, em sua maioria, do quadro de temporários, como destacado no portal de transparência do estado de Goiás no ano de 2018, que aponta que, dos 3898 servidores, 1653 são efetivos e 1862 são temporários, sendo que, destes, aproximadamente 900 exercem o cargo de professor. 78 


\section{REVISTA ELETRÔNICA \\ DA GRADUAÇÃO/PÓS-GRADUAÇÃO EM EDUCAÇÃO UFG/REJ}

docentes em regime de contrato temporário possuem apenas graduação, e mais de 50\% dos professores contratados possuem apenas especialização. Um fato que agrava essa questão é que, a despeito de os contratos temporários serem renovados a cada três anos, o docente não precisa interromper o mesmo e nenhum afastamento é requerido, logo é possível encontrar docentes com 19 anos atuando em sala na UEG, o que cria, para eles, uma falsa ideia de direitos que, de fato, não lhes são garantidos por lei.

Sobre essa questão, Favero aponta que:

[...] a prestação do ensino em um ambiente em que não se faz pesquisa, em uma universidade sem laboratórios, com bibliotecas precárias e, sobretudo sem o indispensável pessoal qualificado - professores e alunos em tempo parcial, ou professores horistas - para a produção do conhecimento, para a elaboração de pensamento e a invenção de mecanismos originais, o ensino tende a se tornar estéril e obsoleto (FAVERO, 2004, p. 56).

No ano de 2016, a UEG, por meio da atual Reitoria, anuncia uma reestruturação de cursos por meio do que foi chamado de Redesenho Institucional. Assim,

Com o significativo número de vagas ociosas e baixa demanda em várias unidades, é preciso reconfigurar o portfólio de cursos, ajustandoos de forma mais adequada às demandas qualificadas locais e regionais. Neste sentido, o Conselho Universitário aprovou a substituição de um total de 8 cursos de graduação, com destaque para a implantação do curso de Medicina Veterinária, no Câmpus São Luís de Montes Belos, que apresentou elevada concorrência, com 54 candidatos por vaga no primeiro vestibular (ESTADO DE GOIÁS, 2016, p.467).

O que chama atenção nessa reestruturação é que os cursos que serão substituídos são os de licenciatura, que, como destacado acima, acabaram ficando sem demanda e com vagas ociosas, fato que também deve ser atribuído às mazelas supracitadas vivenciadas pela UEG. Assim, decidiu-se pela abertura de novos cursos, resolução que não contribui para solucionar os problemas da universidade, ao invés de enfrentar os problemas e superar as crises que permeiam as licenciaturas.

O descortinar da realidade da UEG, numa perspectiva de reflexão e de enfrentamento dos problemas, é necessário para se pensar a questão do estágio, visto que o mesmo não se desvincula dessa realidade. Qualquer problema conjuntural ou estrutural na Universidade afetará o bom andamento de qualquer componente pedagógico dos 


\section{REVISTA ELETRÔNICA \\ DA GRADUAÇÃO/PÓS-GRADUAÇÃO EM EDUCAÇÃO UFG/REJ}

\section{ITINEPRARIIUS REFLECTONIS}

ISSN. 1807-9342

Volume 14, N. 2, 2018

cursos de graduação e de pós-graduação, inclusive o estágio obrigatório. É nesse sentido que devemos pensar o estágio nesse universo de avanços e retrocessos enfrentado pela UEG.

A UEG vem tentando estabelecer uma política de estágio, e tem conquistado avanços teóricos em suas resoluções, fato que será analisado na próxima seção.

O caderno 2 de orientações sobre o estágio da Universidade Estadual de Goiás e a Resolução CsA 854/2015: estímulo à formação crítica e reflexiva?

A política de estágio da UEG vem passando por constantes debates. Ao longo destes quase 19 anos de sua existência, foi constituído um caderno para sua orientação e uma resolução voltada para esse componente.

A primeira ação voltada para a constituição de uma política de estágio foi a criação do caderno 2, que se deu no ano de 2006, e que era uma orientação da Política e Regulamentação de Estágio juntamente com a de Atividades Complementares, Trabalho de Curso nos Cursos de Graduação nas Modalidades Licenciatura, Bacharelado e Tecnológicos e Prática como Componente Curricular nos Cursos de Licenciatura da Universidade Estadual de Goiás.

A primeira versão, que teve início em 2006, estava sob a responsabilidade da PróReitoria de Graduação daquele momento, assim os trabalhos foram iniciados a partir de uma Comissão nomeada e constituída por membros da Pró-Reitoria de Graduação, e também por docentes que atuavam nas áreas da Licenciatura e do Bacharelado. No ano de 2007, os trabalhos voltados para a Política e Regulamentação foram retomados sob a responsabilidade da Pró-Reitoria de Graduação daquele momento.

$\mathrm{Na}$ retomada dos trabalhos, foi constatada a necessidade de uma reavaliação do trabalho, de maneira que foi constituída uma Comissão, formada não só por docentes representantes dos cursos de Licenciatura e Bacharelado, mas também por representantes dos Cursos de Tecnologia, além de representantes discentes.

A metodologia estabelecida nos encontros foi, principalmente, o estudo das diversidades existentes na realização dos componentes curriculares em cada Câmpus dessa Universidade. Nessa perspectiva, com relação ao Componente Estágio Curricular Supervisionado, com a intenção de ampliar a reflexão sobre metodologias para a realização do estágio, foram estabelecidos: o conceito de estágio, sua caracterização e 


\section{REVISTA ELETRÔNICA \\ DA GRADUAÇÃO/PÓS-GRADUAÇÃO EM EDUCAÇÃO \\ UFG/REJ}

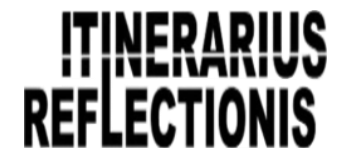

ISSN. 1807-9342

Volume 14, N. 2, 2018

natureza, os campos de estágio, os procedimentos para a sua realização, a supervisão, as atribuições dos profissionais e dos discentes envolvidos no processo, e, por fim, as diretrizes básicas para a realização da avaliação do estágio.

Esse caderno, no entanto, não foi apresentado à comunidade acadêmica tal qual foi elaborado pela comissão supracitada. No ano de 2009, a PRG mudou de pró-reitor e, assim, embora o caderno tenha sido lançado, houve novas mudanças realizadas por uma outra comissão técnica da PRG, que suprimiram muitos anseios dos representantes dos campi.

A partir das análises feitas do referido caderno 2 (versão final), na parte em que se refere ao Estágio Supervisionado, pode-se perceber que a Universidade Estadual de Goiás estimula, de forma tímida, por meio deste caderno, a reflexão-ação-reflexão; notase, porém, algumas contradições nos critérios de avaliação e aprovação, pois este delimita a avaliação em fichas e relatórios (Art. 39 e 40), indo contra a perspectiva da reflexãoação-reflexão e priorizando a dimensão técnica.

Por outro lado, percebe-se, ao longo do referido caderno, que a dimensão teóricoprático já era cunhada, ainda que de forma tímida. Outro fator positivo foi o estabelecimento de que o aluno deveria fazer um projeto de estágio. Em contrapartida, um elemento negativo e preocupante era o fato de não haver critérios para a escolha do professor orientador, bem como a exigência apenas da especialização para a função de coordenador.

É preciso destacar ainda que, embora, a princípio, o caderno tenha sido construído por meio de representatividade, ele não foi fundamentado por um estudo e debate das condições do estágio, assim, o mesmo se caracterizou por um documento regulador pautado praticamente na legislação nacional.

Ao longo dos anos, a UEG passou por transformações que demandaram novas perspectivas para se pensar o estágio, assim surge a resolução CsA 854/2015. Essa resolução foi construída a partir de um Grupo de Trabalho constituído em março de 2014, com o objetivo de apresentar proposições/orientações/diretrizes para reestruturar o Estágio Curricular Supervisionado da UEG.

Esse GT destacou como principal problemática a dicotomia entre teoria e prática, que, por sua vez, priorizava a formação teórica e privilegiava uma concepção de prática como momento de aplicação da teoria; o GT destacou, também, que o conhecimento 


\section{REVISTA ELETRÔNICA \\ DA GRADUAÇÃO/PÓS-GRADUAÇÃO EM EDUCAÇÃO \\ UFG/REJ}

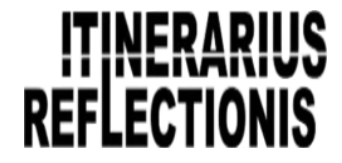

ISSN. 1807-9342

Volume 14, N. 2, 2018

científico era produzido pela pesquisa e relacionado com a teoria e a prática desprovida de saberes; as práticas eram ministradas no final do currículo e se restringiam em fornecer apenas técnicas de ensino; por fim, ainda foram apresentadas, pelo GT, algumas consequências do modelo de estágio que a UEG estava adotando, dentre as quais destacamos a ausência de uma proposta teórica, a inexistência de critérios institucionalizados de ações dos professores orientadores e carência de sistematização das ações (KHAOULE, 2014).

Analisando a Resolução CsA 854/2015, percebe-se que a concepção de estágio supervisionado valoriza a perspectiva teórico-prática, numa perspectiva reflexiva, crítica e investigativa da formação, cabendo ao curso propor suas produções acadêmicas para avaliar o estágio, considerando que as mesmas sejam contínuas e contextuais; investigativas e diagnósticas; dinâmicas, coletivas e compartilhadas; sistemáticas e objetivas.

Ainda conforme a referida Resolução, o estágio supervisionado é o ato educativo de formação profissional desenvolvida no ambiente de trabalho articulado às outras atividades realizadas na Universidade Estadual de Goiás (UEG). E é importante que o estágio promova a aproximação e diálogo da Universidade com os campos de estágio e a sociedade, e entenda os campos de estágio como espaço formativo e articulador entre teoria e prática no processo de formação humana e profissional.

Outro fato que chama atenção é a preocupação com os critérios para a seleção do coordenador adjunto de estágio, tais como ser eleito pelos seus pares, dentre os professores orientadores de estágio supervisionado do curso ou do Câmpus; pertencer, preferencialmente, ao quadro efetivo da instituição, e ser integrante de grupo ou de núcleo de estudos e pesquisas em estágio. Vale destacar que era e ainda é comum essas coordenações serem entregues a docentes que não possuem competência e habilidade para estimular o desenvolvimento do estágio na perspectiva crítica e reflexiva, logo, os critérios supracitados podem favorecer a escolha de um coordenador apto a instigar um estágio em tal perspectiva.

Por fim, a perspectiva de formação continuada dos docentes também foi outra política de suma importância constituída nessa resolução. Nela, é apontada a importância da constituição de núcleos, centros de estudos e pesquisas em estágio, fato que pode contribuir para superar as mazelas que permeiam a execução do estágio. 


\section{REVISTA ELETRÔNICA \\ DA GRADUAÇÃO/PÓS-GRADUAÇÃO EM EDUCAÇÃO \\ UFG/REJ}

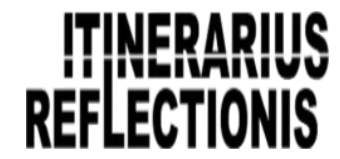

ISSN. 1807-9342

Volume 14, N. 2, 2018

Outra questão relevante, e que será abordada adiante, é a forma como os alunos representam o estágio supervisionado obrigatório, na medida em que nos permite pensar esse componente a partir do olhar de quem o vivencia, ampliando as possibilidades de repensar as ações numa perspectiva crítica e reflexiva.

\section{O ESTÁGIO EM GEOGRAFIA NA REPRESENTAÇÃO SOCIAL DOS ALUNOS}

O estágio realizado na Geografia da UEG no Câmpus de Formosa vem sofrendo mudanças, muitas das quais impulsionadas por novos olhares e, até mesmo, em função das novas diretrizes constituídas pelas políticas de estágio da UEG. Assim, antes de analisarmos a representação social dos alunos sobre esse componente, vamos caracterizar o estágio numa perspectiva de mudanças recentes.

\section{O caminhar do estágio Obrigatório no curso de Geografia na UEG Câmpus Formosa}

Antes de iniciarmos a caracterização e análise do curso de Geografia, é preciso ressaltar que, no Câmpus de Formosa, se observarmos a política atual de estágio, podemos perceber que ainda existem entraves para sua consolidação, dentre estes podemos citar a dificuldade para implantar metodologias investigativa e crítica, o não cumprimentos dos critérios para a escolha do coordenador adjunto, bem como a ausência de núcleos de estudo e pesquisa ligados ao estágio.

O estágio na Geografia segue o que foi preconizado na legislação nacional, e, portanto, tem início na metade do curso, isto é, no $3^{\circ}$ ano. Fica sob a responsabilidade de quatro professores orientadores, dois para orientar os alunos do $3^{\circ}$ ano, e dois para orientar os do $4^{\circ}$ ano. No curso de geografia, ainda há um componente pedagógico atrelado ao estágio, como a disciplina de Prática Pedagógica (anteriormente designada Didática e Prática de Ensino). É preciso destacar, também, que o curso está passando de regime anual para semestral. Assim, quando anual, o estágio era atrelado em duas disciplinas; com a semestralidade, passa a ter quatro disciplinas.

Nos anos de 2012 e 2013, havia um projeto de estágio para todo o Câmpus. Era um manual que orientava como deveria ser a metodologia do estágio e que, basicamente, era pautado em uma coletânea de estágio que deveria conter, além de elementos pré e pós textuais, também: observação; ficha de identificação da escola; cronograma de 


\section{REVISTA ELETRÔNICA \\ DA GRADUAÇÃO/PÓS-GRADUAÇÃO EM EDUCAÇÃO \\ UFG/REJ}

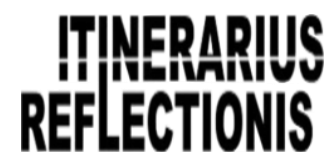

ISSN. 1807-9342

Volume 14, N. 2, 2018

observação das aulas; ficha de frequência; regência; cronograma de atividades/regência; atividades e/ou textos/exercícios complementares das aulas ministradas; ficha de avaliação de regência feita pelo professor regente; ficha de avaliação de regência feita pelo professor supervisor; ficha de avaliação do estágio feita pelo diretor da escola; ficha de frequência (regência); relatórios analítico da observação e da regência; participação em um projeto ligado a educação infantil ( $1^{\circ}$ ao $5^{\circ}$ ano), Projeto Luzes, e, por fim, a participação em outro projeto, intitulado Professor Educador.

O que chama atenção nessa coletânea é justamente o quantitativo de fichas utilizadas para assegurar que o aluno estava realmente fazendo o estágio. $\mathrm{O}$ aluno chegava a preencher mais de 100 delas, pois cada ação era acompanhada por uma ficha assinada pelo professor supervisor de estágio ou o diretor da escola campo. Ao invés de uma metodologia mais investigativa e reflexiva, havia mecanismos de controle da ação dos alunos através das fichas.

Essa metodologia se destacava pelo seu cunho técnico e pela pouca reflexão e criticidade na formação do futuro professor, visto que o único momento em que essa reflexão seria possível era a elaboração dos relatórios; não bastasse isso, a disciplina atrelada a esse componente também estava pautada em uma didática instrumental, em que as miniaulas eram priorizadas como metodologia principal. Muitas vezes, um semestre inteiro seria investido nelas, pois cada aluno deveria expor, em sala, de 30 a 40 minutos de algum conteúdo da Geografia, e, caso não conseguisse ministrar a miniaula segundo os critérios estabelecidos pelo professor, deveria realiza-la novamente, pois a atividade comporia a nota de dois bimestres.

Havia também uma disputa interna, entre os professores, para atuar no componente estágio. Parte dos docentes queria ministrar o estágio, já que, em função da sua complexidade, tinha carga horária total (40h) para os professores em regime de contrato, e, para os efetivos, era permitido diminuir a carga horária em sala; logo, pautados na crença de que o estágio era "fácil", muitos queriam - e ainda querem - atuar no mesmo.

Era comum que professores responsáveis pelo estágio não atendessem critérios como a disponibilidade para acompanhar os alunos nas escolas campo, visto que ocupavam outros cargos em outras instituições por 40 horas, e a necessidade de formação na área de atuação do estágio, ou até mesmo em licenciatura em Geografia. Isso também 


\section{REVISTA ELETRÔNICA \\ DA GRADUAÇÃO/PÓS-GRADUAÇÃO EM EDUCAÇÃO \\ UFG/REJ}

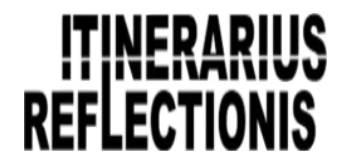

ISSN. 1807-9342

Volume 14, N. 2, 2018

justificava o volume de fichas, pois muitos professores só iam à escola campo para assistir uma aula que era vista como aula-prova, momento em que o aluno era avaliado quanto a sua capacidade de "dar aulas".

Havia também um entendimento de que o estágio era momento prático, logo, a disciplina que estava atrelada ao estágio não deveria se preocupar com as teorias que embasam o estágio, assim, as aulas se pautavam, muitas vezes, em momentos para falar sobre o estágio que ocorria nas escolas campo.

A partir do ano de 2014, algumas mudanças começaram a tomar lugar, em parte em função dessa pesquisa aqui apresentada, em parte pela mudança de Gestores da UEG Câmpus Formosa - que passou a dar mais abertura para mudanças -, e em parte, ainda, pelo fato da UEG ter iniciado também um debate para pensar em seu próprio estágio, que culminou na Resolução CsA 854/2015.

As reflexões promovidas por essa instituição estimularam novas perspectivas ligadas ao estágio, mais relacionadas à investigação, e também os professores de estágio buscaram novas perspectivas. Havia, no curso, uma professora que iniciou um projeto numa perspectiva mais investigativa, e, assim que foi implantada a Resolução CsA 854/2015, o curso resolveu abraçar o único projeto que adotava essa perspectiva, já que o mesmo ia de encontro com a referida Resolução.

Esse projeto, com base na pesquisa-ação, foi constituído na perspectiva de se pensar o estágio teórico-prático, com metodologia voltada para a investigação e reflexão, tendo como embasamento autores como Selma Garrido Pimenta, Evandro Guedin, Isabel Alarcão, dentre outros, que se preocupam em romper com a didática instrumental, e valorizam a pesquisa na formação de professores críticos e reflexivos.

Assim, nesse projeto, o aluno passa a fazer pesquisa da realidade da escola e da sala de aula a partir de observações in loco. Também levanta uma problemática ligada à aprendizagem em geografia, e propõe um projeto de estágio que abarca não só a problemática e uma revisão bibliográfica, mas, principalmente, as metodologias e sua previsão de aplicação. Esse projeto é confeccionado sob a orientação do professor orientador de estágio, e sob avaliação e aprovação do professor supervisor da escola campo.

O aluno aplica uma pesquisa-ação norteada pelo projeto supracitado e, assim, conclui sua regência em sala, escrevendo, por fim, um artigo em que analisa os resultados 


\section{REVISTA ELETRÔNICA \\ DA GRADUAÇÃO/PÓS-GRADUAÇÃO EM EDUCAÇÃO \\ UFG/REJ}

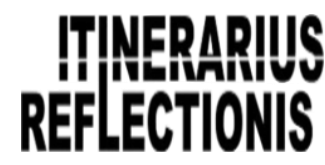

ISSN. 1807-9342

Volume 14, N. 2, 2018

da pesquisa-ação. Vale destacar que, nesse momento de confecção do artigo, o aluno é convidado a pensar sobre sua ação na escola numa perspectiva do professor crítico reflexivo que, para Alarcão (1996), é aquele que pensa a si mesmo que reflete sua ação numa perspectiva de criticar, reavaliar e reinventar a ação docente.

Findado o artigo, os resultados do estágio são partilhados na Universidade a partir de uma culminância como seminário aberto a alunos, comunidade universitária e escola campo. Nesse projeto, também é previsto que os alunos levem uma devolutiva para a escola, de modo que eles devem entregar os resultados da pesquisa para a escola. É sugerido que o projeto e o artigo final sejam entregues em um CD.

As fichas antes tão abundantes foram reduzidas às fichas exigidas pela UGE que, basicamente, exigem a observação e regência realizadas no estágio. Nas disciplinas atreladas ao estágio, não há exigência de miniaulas, mas é preciso estimular o exercício da docência por meio de atividades que priorizem a exposição da compreensão das teorias ligadas ao estágio.

As disciplinas foram constituídas a partir de bibliografias, que devem, em tese, dar suporte teórico ao estágio, de maneira que suas ementas sugerem a abordagem da perspectiva da pesquisa-ação, do professor crítico reflexivo, das diferentes concepções de estágio, das categorias de análise em Geografia aplicadas ao ensino, dos currículos em geografia, da análise do livro didático, dos procedimentos de ensino em geografia, das novas tecnologias no ensino e da importância da avaliação. Essas disciplinas deveriam continuar sendo momento de orientação e de partilha das experiências ligadas ao estágio, mas, agora, com suporte teórico para as reflexões sobre as ações dos alunos em experimentação docente.

No entanto, embora o projeto de estágio seja o mesmo para todo o curso de geografia, a metodologia de execução e o acompanhamento do estágio são distintos, pois trata-se de quatro professores orientadores, de forma que dois professores caminham sempre juntos, do início ao fim do estágio na disciplina de Prática Pedagógica. Já os outros dois professores optaram por juntar a turmas em momentos específicos, entendendo que dariam um suporte maior aos alunos.

De modo geral, a metodologia do estágio no curso de Geografia toma corpo segundo o trabalho de cada professor. Assim, é comum a exigência das miniaulas e fichas na metodologia de dois professores, e também a manifestação desses professores sobre a 


\section{REVISTA ELETRÔNICA \\ DA GRADUAÇÃO/PÓS-GRADUAÇÃO EM EDUCAÇÃO \\ UFG/REJ}

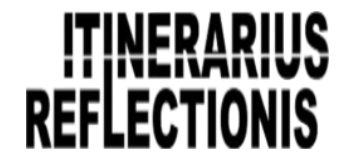

ISSN. 1807-9342

Volume 14, N. 2, 2018

preferência por relatórios ao invés de artigos para trabalhar o resultado da pesquisa, o que nos leva afirmar que é difícil alterar, de fato, uma cultura ou um paradigma. A perspectiva de núcleo de estudo apontada na Resolução CsA 854/2015 é um caminho para mudar algumas perspectivas, mas sua realização ainda sequer foi cogitada no Câmpus de Formosa.

Devemos, por fim, considerar que a universidade é uma instituição social, logo, sujeita à cultura impulsionada e vivenciada por seus sujeitos. Nesse sentido, não se pode descartar os vieses e as possibilidades de mudanças que podem vir por meio do diálogo, dos embates e de mudanças do quadro de professores, dentro de uma perspectiva de concursos para professores efetivos.

\section{As teorias da representação social e sua importância para pensar o estágio numa perspectiva crítica-reflexiva}

O estágio, numa perspectiva crítica e reflexiva, se atrela a concepção do professor reflexivo crítico. Nesse contexto, devemos considerar que a reflexão aqui proposta, ligada a esse conceito, não se dá apenas no contexto individual, mas, dentro de um coletivo de sujeitos que mobilizam os saberes nas escolas. Ainda, devemos considerar que o professor não deve fazer a separação de sua prática do contexto organizacional no qual ocorre, tão pouco, descolado da sociedade.

O professor, reflexivo crítico, realiza suas reflexões dentro de um contexto escolar e, junto de um coletivo de professores para repensar suas práticas como possibilidade de mudança da realidade. Posto isso, devemos pensar qual tem sido a representação social dos alunos do curso de Geografia, nessa perspectiva supracitada.

Assim para as reflexões teóricas ligadas ao estágio que ocorre no curso de Geografia da UEG Câmpus Formosa, buscamos as teorias da representação social, que auxiliam a compreender as concepções que os alunos têm sobre o estágio obrigatório no curso de Geografia.

Na década de 1960, Serge Moscovici, partindo das teorias de Durkhein sobre representação, cria as teorias da representação social na Europa, que se expandiram para a América Latina. A representação social tem sua origem na psicologia social.

Partimos da concepção de que a representação social é a representação de alguma coisa ou de algum objeto e se caracteriza, segundo Jodelet (2001, p. 22), como uma forma 


\section{REVISTA ELETRÔNICA \\ DA GRADUAÇÃO/PÓS-GRADUAÇÃO EM EDUCAÇÃO \\ UFG/REJ}

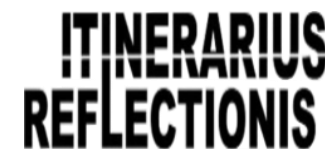

ISSN. 1807-9342

Volume 14, N. 2, 2018

de conhecimento, socialmente elaborada e partilhada com um objetivo prático, que contribui para a construção de uma realidade comum a um conjunto social. Ainda:

[...] fala tanto quanto mostra, comunica tanto quanto exprime. No final das contas, ela produz e determina comportamentos, pois define simultaneamente a natureza dos estímulos que nos cercam e nos provocam, e o significado das respostas a dar-lhes (MOSCOVICI, 1978, p. 26).

Também consiste em "sistemas de interpretação que regem nossa relação com o mundo e com os outros e organizam as condutas e as comunicações sociais" (JODELET, 2001, p.22). Pode-se, com essa definição, destacar que é a partir das nossas representações sociais que formamos conceitos, imagens, símbolos, etc.; construímos nosso saber, enfim, com base no senso comum.

A representação social não está desvinculada da ideologia, é parte e/ou criação desta e vice-versa. Entretanto, Madeira (1991, p.137) destaca que "a ideologia tem um caráter geral e aí está sua fluidez, sua ambiguidade e, por isso mesmo, sua força. A representação, ao contrário, se constrói e articula em torno de objetos definidos".

Por isso, a representação social é muito importante em pesquisas educacionais, posto que permite identificar como é interpretado e representado o estágio, o que ele simboliza e como os alunos e professores interagem com ele. É a partir dessa teoria que foi realizada a pesquisa de campo com entrevistas aos alunos do curso de Geografia nos anos de 2012, 2013, 2016 e 2017.

\section{O Estágio Obrigatório na representação social dos alunos do curso de Geografia em 2012 e 2013}

Ressaltamos que, como, nesse período, a metodologia ligada ao estágio dos quatro professores era semelhante, visto que eles seguiam o projeto de estágio proposto para tal período pautado em coletânea, apresentamos os dados ligados à representação social dos alunos aglutinando as respostas dos alunos do $3^{\circ}$ e do $4^{\circ}$ ano em Geografia.

Conhecer um pouco da realidade dos alunos é importante para delinear o perfil dos sujeitos que estão envolvidos no estágio, já que suas particularidades são relevantes para adaptação e execução das metodologias de ensino-aprendizagem. 


\section{REVISTA ELETRÔNICA \\ DA GRADUAÇÃO/PÓS-GRADUAÇÃO EM EDUCAÇÃO \\ UFG/REJ}

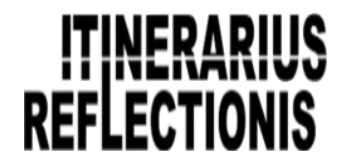

ISSN. 1807-9342

Volume 14, N. 2, 2018

Quanto aos aspectos socioeconômicos dos alunos do Câmpus de Formosa que cursavam o estágio nos anos de 2012 e 2013, percebe-se que sua a idade variava respectivamente entre 20 a 31 anos e 20 a 34 anos de idade, predominando a idade de 20 anos. Nesse período, o curso de Geografia recebia alunos de diversas cidades, sendo a maior concentração oriunda dos municípios de Formosa, Planaltina do Distrito Federal e Planaltina de Goiás.

Sobre o estágio, podemos perceber que dentre os principais critérios adotados pelos acadêmicos para escolher a escola campo de estágio estão a proximidade da residência ou do trabalho, bem como horários acessíveis para sua rotina.

Aproximadamente $61 \%$ dos acadêmicos consideram que não houve interação entre a UEG Câmpus Formosa e a escola campo, argumentando, principalmente, a limitação entre observação e regência, apenas o fornecimento dos instrumentos legais, bem como o fato de fazerem essa interação sozinhos.

No que diz respeito à forma que o professor supervisor da escola campo contribuiu para a formação do acadêmico, percebe-se, nas respostas dos acadêmicos, que o professor regente auxilia, nos momentos da regência, com conselhos, dicas, observação das aulas, disponibilização de livros, apoio relacionado à manutenção do modelo observaçãoregência. Ainda, $85 \%$ dos alunos afirmaram que puderam vivenciar a realidade escolar de forma a repensar a prática na escola campo em que estagiaram.

Os alunos enfatizaram, como ponto positivo, o fato do estágio proporcionar um maior contato com a realidade escolar; como ponto negativo, $80 \%$ dos alunos citava a metodologia adotada no estágio, principalmente a "coletânea de estágio", trabalho que era feito para ser entregue ao fim do Estágio, bem como as fichas. Algumas de suas observações foram: "são muitas fichas e assim gasta-se mais tempo preparando o "Portfólio" do que regendo aulas", "Sistema muito metódico e burocratizado, muita ficha para preencher", dentre outras.

Ainda, 79\% dos acadêmicos do $3^{\circ}$ e $4^{\circ}$ ano de Geografia do Câmpus Formosa gostariam que o Estágio ocorresse desde os primeiros anos do curso, e defendem essa posição argumentando, principalmente, o excesso de atividades que acumulam no $4^{\circ}$ ano.

Quando são perguntados se se sentem preparados para a docência ao término do estágio, e por que, $61 \%$ dos acadêmicos pesquisados responderam que não, porque se faz necessária uma análise de possibilidades, bem como do universo do aluno em que se 


\section{REVISTA ELETRÔNICA \\ DA GRADUAÇÃO/PÓS-GRADUAÇÃO EM EDUCAÇÃO \\ UFG/REJ}

\section{ITWERAPUS \\ REFLECTIONIS}

ISSN. 1807-9342

Volume 14, N. 2, 2018

leciona. Alguns argumentam que só se aprende verdadeiramente com a atuação na sala de aula, criticando também o pouco tempo do estágio.

Por fim, $70 \%$ dos alunos entendiam o estágio como momento de prática, argumentando que é o momento de colocar em prática o que aprenderam na universidade. Aqui, se percebe que o estágio é pensado apenas em sua dimensão prática.

\section{O Estágio Obrigatório na representação social dos alunos no curso de Geografia em 2016 e 2017}

Como já destacamos anteriormente, embora o projeto de estágio do curso de Geografia nesse período fosse o mesmo, a metodologia de execução, assim como o acompanhamento do estágio divergiam. Assim, optamos por apresentar a representação sobre o estágio separadamente, de acordo com cada ano.

Realizamos pesquisa com duas turmas de estágio, a primeira com a turma do $3^{\circ}$ ano do curso de licenciatura em geografia da Universidade Estadual de Goiás Câmpus Formosa, composta por 23 alunos frequentes, cuja idade variava de 19 a 35 anos. As cidades em que residiam eram predominantemente Formosa, seguida de Planaltina do Distrito Federal.

Quanto ao estágio, foi possível perceber que o critério para escolher a escola campo de estágio está ligado à afinidade com a escola campo, pela convivência e por serem bem recepcionados pela direção e professores, bem como à proximidade de casa ou do trabalho. $12 \%$ não responderam à questão.

Perguntamos se houve uma interação eficiente entre a UEG, Câmpus de Formosa e a escola campo de estágio, possibilitando ao aluno estagiário mais do que observar aulas; $41 \%$ dos alunos responderam que não houve essa interação ou não perceberam essa interação, $41 \%$ disseram que sim, houve interação dos professores, e $18 \%$ não responderam.

Quando foi perguntado aos alunos o que é estágio supervisionado, eles responderam dentre outras "que é uma oportunidade de conhecer a realidade e colocar a prática em ação é um momento de decisão para saber se realmente a pessoa quer ser um professor", e ainda que é o momento de mostrar o que aprendeu na prática e sua autonomia intelectual, ainda responderam que "é uma disciplina normal". 


\section{REVISTA ELETRÔNICA \\ DA GRADUAÇÃO/PÓS-GRADUAÇÃO EM EDUCAÇÃO UFG/REJ}

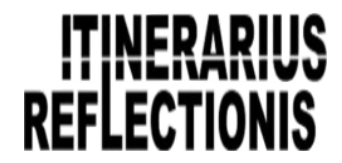

ISSN. 1807-9342

Volume 14, N. 2, 2018

Sobre os pontos positivos do estágio, os alunos apontaram a motivação, experiência e bagagem de conhecimentos, as turmas boas de trabalhar, oportunidade de vivenciar a escola, apoio da escola, alunos interessados, ofato de não ter problemas com a classe. Sobre os pontos negativos, a maioria (29\%) destacou o desinteresse dos alunos, os conteúdos da disciplina, a falta de disciplina dos alunos, a estruturas totalmente precárias das escolas, salas muito lotadas e falta de alguns recursos didáticos. Outros observaram que o curto período de aulas reduzidas atrapalha a finalização da aula de forma planejada, e 18\% destacaram a pouca interação entre a Universidade e a escola, falta de suporte da UEG e orientação por parte dos professores do estágio. Também houve alunos que relataram que não tiveram domínio da turma porque trabalham, o que acabou atrapalhando a execução do estágio.

Quando foi perguntado se eles acreditam que o estágio supervisionado lhes propicia uma vivência que possibilita repensar suas próprias teorias e práticas, $76 \%$ respondeu que acredita que sim, porque o estágio, como pesquisa, possibilita aos graduandos pensar e repensar a sua prática, podendo assim desenvolver melhores metodologias; $18 \%$ disseram que não, justificando que o professor que ajuda a ministrar o estágio supervisionado não lhes dá atenção suficiente; $6 \%$ dos alunos não responderam.

Ainda, $59 \%$ dos alunos acreditam que o estágio deveria iniciar nos primeiros anos do curso de Geografia, pois isso lhes possibilitaria maior interação com a realidade escolar, podendo leva-los a pensar em melhores metodologias; $29 \%$ acham que o melhor momento para iniciar o estágio é, de fato, no $3^{\circ}$ e $4^{\circ}$ ano, justificando que este é o período certo para a execução do estágio, já que reger uma aula requer uma bagagem de conhecimentos; $6 \%$ acreditam que deveria começar no $2^{\circ}$ ano, para que possam decidir se querem ser professores ou não; $6 \%$ não responderam.

Outra pesquisa foi realizada com os 13 discentes do curso de Geografia do $4^{\circ}$ ano de 2016, turma que era composta por 14 alunos frequentes, através de entrevista com roteiro dirigido com o objetivo de verificar a representação social que os discentes tinham do estágio supervisionado em Geografia do Câmpus Formosa. Os alunos residiam em Formosa e Planaltina de Goiás, e sua idade variava de 21 a 23 anos.

Sobre o estágio, percebemos que quanto ao fator que os levou a escolher a escola campo de estágio, $60 \%$ dos alunos apontaram o fato de terem sido bem recebidos em um primeiro contato proporcionado no estágio. Os outros destacaram afinidade com a escola 


\section{REVISTA ELETRÔNICA \\ DA GRADUAÇÃO/PÓS-GRADUAÇÃO EM EDUCAÇÃO \\ UFG/REJ}

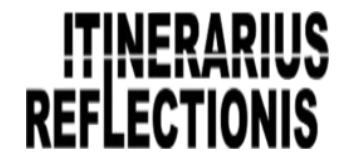

ISSN. 1807-9342

Volume 14, N. 2, 2018

e a proximidade de casa. Vale destacar que, durante o estágio, os alunos fazem pesquisa nas escolas do município de Formosa para conhecer a realidade das mesmas e só então partem para a escolha da escola campo.

Quanto à interação entre a escola e o estágio, 80\% dos alunos pontuam que houve boa interação, mas $20 \%$ discordam, afirmando que faltou mais participação do professor da escola campo.

Sobre os pontos positivos e negativos ligado ao estágio, os alunos destacaram como positivo: onde podemos refletir; sensação de ser de fato um professor, podendo vivenciar a escola campo; permissão de uma ação-reflexão das minhas práticas; obtenção de mais preparação e autonomia; descoberta da identidade; compreensão da importância da auto avaliação do professor e a importância da pesquisa. Já quanto aos pontos negativos, foram destacados: falta de colaboração por parte da direção escolar; não poder fazer o estágio em Planaltina-DF; falta de organização da escola a respeito dos horários de aulas; falta de comunicação entre o professor supervisor da escola campo com o estagiário; pouco tempo, programação da escola, dificuldade em aplicar as aulas.

Ainda, $80 \%$ dos alunos entendem o estágio como momento de experimentar a docência, destacando que o mesmo é teórico-prático. 100\% dos alunos entrevistados acreditam que o Estágio Supervisionado, tal como é executado atualmente, propicia uma vivência que possibilita repensar a sua prática, bem como a realidade escolar, no entanto $50 \%$ pontuou que não se sentem preparados para serem professores, justificando que são necessárias uma constante preparação e uma experiência que se faz nas práxis do dia a dia na escola.

Por fim, a representação dos alunos sobre o estágio tem mudado. A metodologia do estágio deixou de ser um dos pontos negativos desse componente. A perspectiva de pensar o estágio como momento só de prática tem se tornado distante, dando lugar a teórico-prático. Também, podemos destacar mudanças na ampliação da participação do professor supervisor de estágio. Por outro lado, algumas representações ainda permanecem tais como a ausência de interação entre a escola campo e a universidade, assim como, os critérios adotados para a escolha das escolas campo de estágio.

\section{CONSIDERAÇÕES FINAIS}




\section{REVISTA ELETRÔNICA \\ DA GRADUAÇÃO/PÓS-GRADUAÇÃO EM EDUCAÇÃO UFG/REJ}

Os resultados aqui apresentados são relevantes para se pensar o papel do estágio numa perspectiva de formação pautada na reflexão crítica. Podemos afirmar que no curso de Geografia houve a superação de parte da metodologia que supervaloriza as fichas e os relatórios que, em sua maioria, se apresentam como mecanismos de acompanhamento e regulação do estágio. O projeto de estágio do curso de Geografia apresenta, ainda, uma perspectiva que possibilita implantar uma formação de teor investigativo, crítico e reflexivo.

Entretanto, embora a maioria dos alunos aponte a importância do estágio na sua formação como professor de Geografia, percebemos que os alunos ainda têm dificuldade de vislumbrar o estágio para além da observação e da regência, isto é, eles não consideram a teoria como momento integrado ao estágio.

Fatores a serem também destacados são os critérios adotados pelos alunos para escolher a escola campo. Esse momento deveria extrapolar os inconvenientes de estagiar em uma escola que está distante de sua residência; o critério de escolha deveria ser aquele que levasse o aluno a vivenciar a docência de forma reflexiva, e, para isso, muitas vezes as escolas que não fazem parte da tradição pedagógica podem contribuir de forma mais efetiva e eficiente.

Outro fato relevante é repensar o papel e o lugar do estágio nos cursos de formação de professores, pois esse componente poderia articular-se com outros componentes, assim como com outras disciplinas, de forma a instigar o aluno a vivenciar a escola desde o primeiro ano do curso. É fato que a prática como componente pedagógico propõe-se a isso, mas, na verdade, foi ainda pouco discutida nos cursos de formação de professores e tomou outros rumos no cotidiano da sala de aula dos cursos superiores.

Assim, é notório que o estágio no curso de Geografia ainda necessita de reformulações e de uma maior interação entre os sujeitos envolvidos, de maneira a contribuir satisfatoriamente no desenvolvimento desse componente. Vale ressaltar a necessidade de o estágio ser trabalhado de forma a integralizar as partes que o constituem, posto que o mesmo ainda se alicerça em perspectivas que o entravam, como a falta de diálogo entre os professores supervisores, a não participação dos professores das escolas campo no planejamento do estágio, e a perspectiva, de parte dos professores, centradas na didática instrumental. 


\section{REVISTA ELETRÔNICA \\ DA GRADUAÇÃO/PÓS-GRADUAÇÃO EM EDUCAÇÃO UFG/REJ}

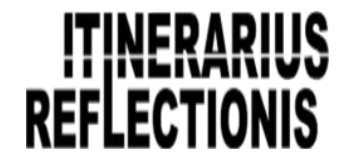

ISSN. 1807-9342

Volume 14, N. 2, 2018

O estágio, na perspectiva da reflexão crítica, precisa ser um projeto resultante do anseio de todo o curso, particularmente de anseios dos alunos, professores orientadores e professores das escolas campo, além disso, a metodologia precisa instigar a açãoreflexão-ação de forma que o professor orientador se liberte da obrigação de criar mecanismos de aferição da efetiva participação do aluno no estágio. O professor deveria, enfim, se preocupar e se ocupar em refletir a ação docente com o aluno, e não se preocupar com sua efetiva participação de forma muitas vezes mecânica, que se traduz em atividades cansativas e enfadonhas para os futuros professores de Geografia.

O projeto de estágio do curso de geografia se alinha na perspectiva da política de estágio da UEG, entretanto, suas práxis carecem de ações alicerçadas no diálogo entre os sujeitos que executam esse componente pedagógico, para assim superar os desafios ainda presentes.

Por fim, percebe-se que os problemas ligados ao estágio são também resultantes dos problemas enfrentados pela UEG, afinal, como já advertimos, os problemas conjunturais ou estruturais na Universidade afetam o bom andamento de qualquer componente pedagógico dos cursos de graduação e de pós-graduação, inclusive o estágio obrigatório.

\section{REFERÊNCIAS}

ALARCÃO, Isabel. (org.). Formação reflexiva de professores - estratégias de supervisão. Editora Porto. Porto, Portugal, 1996.

BARREIRO, Iraíde Marques de Freitas; GEBRAN, Raimunda Abou. Breve histórico da prática de ensino nos cursos de formação de professores. In: _. Prática de ensino e estágio supervisionado na formação de professores. São Paulo: Avercamp, 2006. cap. 2.

GHEDIN, Evandro. Estágio, pesquisa e a produção do conhecimento na formação de professores (as). Ponta Grossa, 2004. p. 57-76.

ESTADO DE GOIÁS. Controladoria Geral de Goiás. Consolidação das Ações e Programas dos Órgãos e Entidades - Exercício 2016. Volume II. Disponível em: http://www.transparencia.go.gov.br/portaldatransparencia/demonstrativos-fiscais/acoese-programas-dos-orgaos-e-entidades. Acesso em: 15 janeiro de 2018.

ESTADO DE GOIÁS. Goiás transparente. Folha de Pagamento - Cargos e Tipos de Vínculo por Órgão. 2018. Disponível 


\section{REVISTA ELETRÔNICA \\ DA GRADUAÇÃO/PÓS-GRADUAÇÃO EM EDUCAÇÃO UFG/REJ}

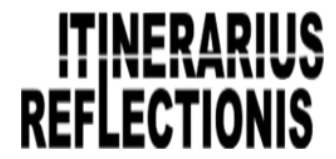

ISSN. 1807-9342

Volume 14, N. 2, 2018

em:http://www.transparencia.go.gov.br/lai.php?painel=folha_de_pagamento_cargos_po r_orgaos\&orgao=ueg. Acesso em: 20 de janeiro de 2018.

FAVERO, M. de L. A. Universidade e estágio curricular: subsídios para a discussão. In: ALVES, N. (Org). Formação de professores: pensar e fazer. São Paulo:Cortez, 2004.

JODELET, D. Representações sociais: um domínio em expansão. In: As representações sociais. Rio de janeiro: Ed: UERJ. 2001. p. 17-44.

KHAOULE A. M. K. Orientações/proposições do GT de Estágio para a (re)construção dos PPC's da Universidade Estadual de Goiás. Disponível em: http://www.cdn.ueg.br/source/grupo_de_trabalho_de_estagio_curricular_156/conteudo N/3505/Apres_Subsidiar_PPCS.pptx_apresentao_FINAL1.pdf. Acesso em 15 de janeiro de 2016.

MADEIRA, M. C. Representações Sociais: Pressupostos e Implicações. R. bras. Est. pedag. Brasília, 72(1711:129-144, maio/ago. 1991. Disponível em: < www.rbep.inep.gov.br/index.php/RBEP/article/view/433/438 > acesso em: 02 de agosto de 2010.

MOSCOVICI. S. A representação social da psicanálise. Rio de Janeiro: Ed Zahar Editores, 1978. 291p.

PIMENTA, Selma Garrido; LIMA, Maria Socorro Lucena. Estágio e Docência. In: Estágio: diferentes concepções. São Paulo: Cortez, 2004. p. 33-57.

UNIVERSIDADE ESTADUAL DE GOIÁS. Resolução CsA N. 854, de 18 de novembro de 2015. Regulamento das Diretrizes Básicas para o Estágio Supervisionado dos Cursos de Graduação da Universidade Estadual de Goiás. Anápolis 2015.

UNIVERSIDADE ESTADUAL DE GOIÁS. Caderno 2 de orientações. Pró-reitoria de Graduação da UEG. Anápolis. 2015. 